\title{
Removal of Methyl Blue Dye from Aqueous Solution by Adsorption unto Ground Nut Waste
}

\author{
Esther Unyime Etim* \\ Department of Chemistry, Nigeria \\ *Corresponding author: Esther Unyime Etim, Department of Chemistry, Nigeria
}

ARTICLE INFO

Received: 㓞 February 07, 2019

Published: March 01, 2019

Citation: Esther Unyime Etim. Removal of Methyl Blue Dye from Aqueous Solution by Adsorption unto Ground Nut Waste. Biomed J Sci \& Tech Res 15(3)-2019. BJSTR. MS.ID.002701.

Keywords: Water Pollution; Dye; Remediation; Adsorption; Ground Nut Shell

\begin{abstract}
The present study was designed to investigate the possibility of using ground nit shell as an adsorbent for the removal of methyl blue dye from aqueous solution. Batch adsorption, FTIR and spectrophotometric methods were used for the study. The results obtained, revealed that the dye has maximum wavelength of absorption at $660 \mathrm{~nm}$ and exhibited infra-red absorption peaks at, 1641, 2966 and $3365 \mathrm{~cm}^{-1}$ which corresponded to $\mathrm{C}-\mathrm{H}$ stretch, $\mathrm{C}=\mathrm{C} / \mathrm{C}-\mathrm{O}$ stretch, $\mathrm{C} \equiv \mathrm{C}$ vibration and $\mathrm{OH} / \mathrm{N}-\mathrm{H}$ stretch. The adsorbent (ground nut shell) also displayed several functional groups that characterized it as a good adsorbent. The adsorbent also exhibited average adsorption capacity of $4.00 \mathrm{mg} / \mathrm{g}$. The adsorption of the dye was strongly favored by low $\mathrm{pH}(<6)$, moderate adsorbent dose and varied linearly with dye concentration and with the period of contact. The adsorption characteristics best fitted the pseudo second order kinetics while the rate of adsorption was significantly affected by intra particle diffusion.
\end{abstract}

The separation factors deduced through the best fitted isotherm (the Langmuir isotherm) revealed that the adsorption of the dye on ground nut shell is favorable. FTIR analysis indicated that the adsorption of methyl dye on ground nut shell is enhance by synergistic interaction between some functional groups in the dye and in the adsorbent. From the results and findings of the study, it was concluded that waste recovered from ground nut shell is a good adsorbent for the removal of methylene blue dye from aqueous solution.

\section{Introduction}

Dyes is one of the commonest organic compounds that are constituents of effluents from dye, leather, textile, pulp/ paper industries. However, their toxicity has attracted volume of researches on best measures that can be used to reduce their impact on aquatic environment. According to Ratna et al. [1] beyond the toxicity of most dye is the tendency for some of them to undergo chemical reactions within the exposed environment and formed products that are more toxic than the primary dye. Klemola et al. [2] evaluated the toxicity of reactive dyes and dyed fabrics using the heap-1-cytotoxicity test. They found that except dye fabrics, all the studied dyes were toxic. Blue dyes were more toxic than red dye. They concluded that all the pure dyes showed toxicity at low concentrations. In his toxicological studied of dye contaminated industrial effluents, Verma [3] found that tannery and dye industrial effluents are more toxic than textile and paper mill effluents. However, all the dye containing industrial effluents were found to exhibit acute toxicity at relative low concentration. It has been found that among all dyes, the toxicity of azo dyes has attracted much environmental concern because they are persistent, relatively non-biodegradable and contains aromatic rings, azoic linkages and amino acids [4].

In view of their potential toxicity and environmental consequences, there is a significant need to develop methods of removing dye from industrial effluents prior to their disposal. Adsorption is known to be one of the best options of detoxifying waste water of dye and dye products [5]. Adsorption is a process of removing pollutants (adsorbate) by allowing them to stick to the surface of suitable materials (adsorbent). Commonly used adsorbent are plant materials (such as plant waste materials), polymer materials (such as zeolite, chitosan, alumina, gypsum, etc) and synthetic materials 
or the blend of one or two of these materials [6-11]. Several factors may affect adsorption of a given dye. For example, Miyah et al. [12] found that the efficiency of walnut shells powder as a low-cost adsorbent for removing methylene blue dye from aqueous solution depends of time, temperature, $\mathrm{pH}$, amount of adsorbent and concentration of dye in the medium. However, the used adsorbent displayed excellent adsorption when these parameters were set at optimum. Manna et al. [12] found that modification of lignocellulosic matter through grafting with neem oil greatly enhance its adsorption capacity for methylene blue dye from aqueous solutions.

Other factors that affected its adsorption capacity were temperature, time, $\mathrm{pH}$ and adsorbent dose. Reddy et al. [3] also found that physical activation of corn cobs with $\mathrm{CO}_{2}$ and steam at high temperature $(1173 \mathrm{~K})$ present excellent adsorption capacity for basic and methylene blue dyes from aqueous solution. The adsorbent was characterized using temperature programme decomposition and thermogravimetric analyzer. Langmuir isotherm best described the adsorption characteristics of the corn com. Some studies have been reported on the use of plant waste as adsorbent for dye. For example, Rehman et al. [13] found that hydrolyzed rice straw biochar obtained from lignocellulosic bioethanol process possessed surface properties (such as Brunauer-Emmet-Teller surface area, total pore volume and pore width) that presents it as a good adsorbent for green dye. The adsorption of the dye was spontaneous and followed a physisorption mechanism. Mono layer of adsorption was affirmed through the fitness of the adsorption data to the Langmuir isotherm. The kinetic of the adsorption was consistent with a second order kinetics. Other plant materials that have been successfully used as adsorbents for dyes include orange peel $[14,15]$ citrus lime peel waste [13], vegetable residue [16], wheat straw [17], macuba palm cake [18], Opuntiaficus indica fruit waste (Pelaez 2013), cashew nut shell [19], oil palm leaves [20], coffee ground [21], peach shell [22], papaya seed [23], switch grass bio char (Mahmound 2016), agricultural waste [24] and seeds of Aleuritemo luccana [25]. Despite all these reported studies, literature is scanty on the use of ground nut shell as an adsorbent for methylene blue and malachite green dyes. Perhaps the most extensive documentation on the use of ground nut shell as an adsorbent for dye is that reported by Kumar et al. [26], who used bed service and Thomas models. The adsorbent was characterized using FTIR, which revealed adsorption peaks at $3398 \mathrm{~cm}^{-1}$ due to $\mathrm{OH}$ stretching, alkane stretching at $2929 \mathrm{~cm}^{-1}, \mathrm{C}=\mathrm{C}$ stretches and C-H bending at 1600 and $1363 \mathrm{~cm}-1$ respectively. Other adsorbents of plant origin have also been reported including hydrothermal carbonized tea waste (Islam 2015), Porous carbon from tea waste [27] camola residue [28] and loofah sponge based porous carbons [29].

Adsorption of compounds such as dyes onto a surface (adsorbent) is control by some factors including, the presence of suitable functional groups, electronic parameters, the presence of lone pair electron, aromaticity and the expected mechanism of adsorption (physical or chemical adsorption). Dyes are either adsorbed through the mechanism of physisorption or chemisorption. Adsorption mechanism involves charge transfer from a charged molecule to charges surface (physisorption) or the transfer of electron from the donor molecule (adsorbate or adsorbent) to the acceptor molecule (adsorbent or adsorbate). Therefore, adsorption of dyes can be considered as a process that involves the creation electrophilic and nucleophilic centers. Because dyes are widely used in our environment and the possibility of experiencing its toxic impact (especially in aqueous media), any method that can reduce the concentration of dye effluence before they are discharge to the environment will contribute to the improvement of environmental quality especially when the process is ecofriendly. Therefore, the present study is aimed at investigating the potential of ground nut shell for the adsorption of Methylene Blue (MB) from aqueous solutions. The chemical structures of MB dye are shown in Figure 1.

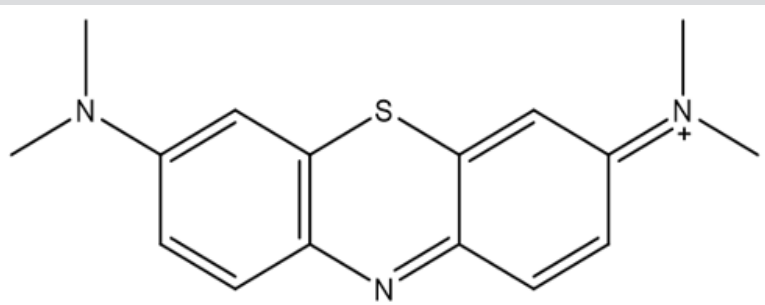

Figure 1: Chemical structure of methyl blue.

\section{Materials and Methods}

Groundnut shell samples were dried to constant weight and sieved to 45 BSS size using an electric shaker. These samples were then used for the adsorption experiment. Annular grades methyl blue and malachite green dyes were purchased from Aldrich chemical company and their respective stock solutions were prepared. All statistical analysis was carried out using excel programmed in the Microsoft software.

\section{Batch Adsorption Experiment}

Batch bio-sorption experiments were conducted as reported elsewhere Mijah et al. [30]. A $250 \mathrm{ml}$ beaker was placed in a shaker maintained at $100 \mathrm{rpm}$. Maximum wavelength of adsorption of the dye was determined by measuring the absorbance values at various wavelengths. A plot of absorbance against concentration was developed and the absorbance that gave highest peak was recorded as wavelength of maximum absorption. All other spectrophotometric experiment were carried out at this wavelength. Calibration curves were prepared using various concentrations (100 to $1000 \mathrm{ppm}$ ) of the dye. From the calibration curve, concentrations of the dye was determined using UV spectrophotometer after absorbance measurements at wavelength of $660 \mathrm{~nm}$. The variables that were investigated through batch adsorption included contact time, initial dye concentration, biomass dose, and solution $\mathrm{pH}$. In each case, the equilibrium concentration of dye adsorbed per gram of the adsorbent was calculated using the following equation [30]. 


$$
q_{e}=\frac{\left(c_{0}-c_{e}\right) V}{m}
$$

where $\mathrm{C} 0$ and $\mathrm{Ce}$ are the initial and equilibrium concentrations of the dye, $\mathrm{V}$ is the volume of sample in liter and $\mathrm{m}$ is the mass of the adsorbent in gram. Effect of concentration was carried out using various concentration of the dye ranging from 10 to $50 \mathrm{mg} / \mathrm{L}$ and agitation rate of $100 \mathrm{rpm}$ for 2 hours. Effect of period of contact and $\mathrm{pH}$ were investigated using fixed mass of adsorbent (2g), constant concentration of the dye (50 mg/L) but varying time (20 to 180 minutes) and $\mathrm{pH}$ (2 to 10 ) respectively. Effect of biomass dose was also investigated by using varying amount of the adsorbent (10 to $100 \mathrm{mg}$ ) but constant concentration of dye (90 mg/l) and time (2 hours) (Mana 2017).

\section{FTIR Analysis}

FTIR analyses of the dye, adsorbent (before and after adsorption) were carried out using Scimadzu FTIR-8400S Fourier transform infra-red spectrophotometer. The sample was prepared using $\mathrm{KBr}$ and the analysis was done by scanning the sample through a wave number range of 400 to $4000 \mathrm{~cm}^{-1}$ [30].

\section{Results and Discussions}

The measured wavelength of maximum absorption of MB dye was $600 \mathrm{~nm}$ while the functional groups identified in FTIR spectrum of the dye were at frequencies of 543, 1641, 2966 and $3365 \mathrm{~cm}^{-1}$. Those in ground nut shell were 3775, 3398, 2930, 1599, 1363, 12581044 and $614 \mathrm{~cm}^{-1}$. Results obtained for the variation of equilibrium amount of MB dye adsorbed with concentration is shown in Figure 2.

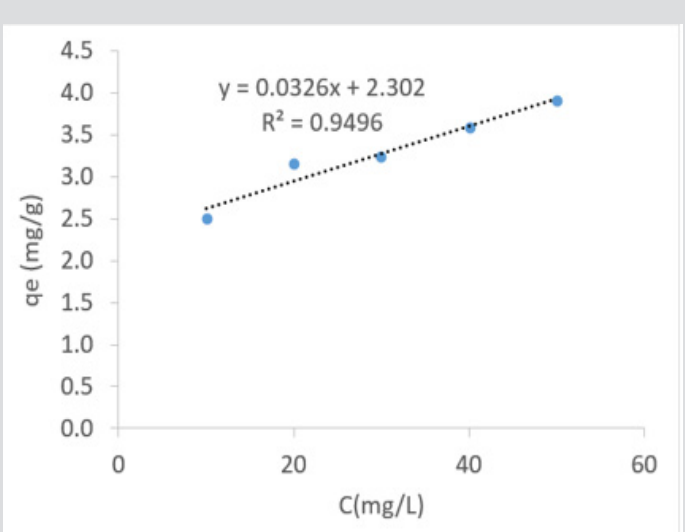

Figure 2: Variation of equilibrium amount of $\mathrm{MB}$ dye adsorbed with concentration.

\section{Spectrophotometric Study}

The absorption spectrum of MB dye indicated that the wavelength of maximum absorption for the dye is $660 \mathrm{~nm}$ which corresponded to value reported by Ghaedi et al. [31]. This wavelength was used as a reference wavelength for measuring all concentrations of MB dye in the study. The FTIR spectrum of MB dye (spectrum not shown) revealed four prominent peaks at 543, 1641, 2966 and $3365 \mathrm{~cm}^{-1}$ which corresponded to $\mathrm{C}-\mathrm{H}$ stretch, C=C/ $\mathrm{C}-\mathrm{O}$ stretch, $\mathrm{C} \equiv \mathrm{C}$ vibration and $\mathrm{OH} / \mathrm{N}-\mathrm{H}$ stretch. Literature reveals that for adsorption to be significant the three must be suitable functional groups through which the adsorbate and the adsorbent can interact, either by electron transfer/formation chemical bond (chemisorption) or charge transfer, which describes physisorption (Eddy 2015). Most suitable functional groups are those having multiple bond or $\pi$-electron [33]. Therefore, MB dye is expected to be effective in creating interactions with ground nut waste, leading to its adsorption.

On the other hand, the FTIR spectrum of groundnut shell indicated the presence of $\mathrm{OH}$ stretches at 3775 and $3398 \mathrm{~cm}^{-1}$, $\mathrm{C}-\mathrm{H}$ stretch at $2930 \mathrm{~cm}^{-1}, \mathrm{C}=\mathrm{C}$ stretch at $1599 \mathrm{~cm}^{-1}, \mathrm{~N}-\mathrm{O}$ stretch at $1363 \mathrm{~cm}^{-1}, \mathrm{C}-0$ stretch as $1258 \mathrm{~cm}^{-1}, \mathrm{C}-\mathrm{N}$ stretch at $1044 \mathrm{~cm}^{-1}$ and alkyl halide stretch at $614 \mathrm{~cm}^{-1}$. After adsorption of MB dye onto the ground nut shell, the $\mathrm{OH}$ stretch was shifted to 3410 , the $\mathrm{C}-\mathrm{H}$ stretch was shifted to 2919 , the $\mathrm{C}=\mathrm{C}$ stretch was shifter to $1536 \mathrm{~cm}^{-1}$ while the $\mathrm{C}-\mathrm{N}$ stretch was shifted to $1050 \mathrm{~cm}^{-1}$. Other functional groups were missing. These shifts were generally observed to occurred ay higher intensity suggesting that there must have been synergistic interaction (between some common functional groups in the ground nut shell and MB dye) that resulted on constructive interference.

\section{Batch Adsorption Study}

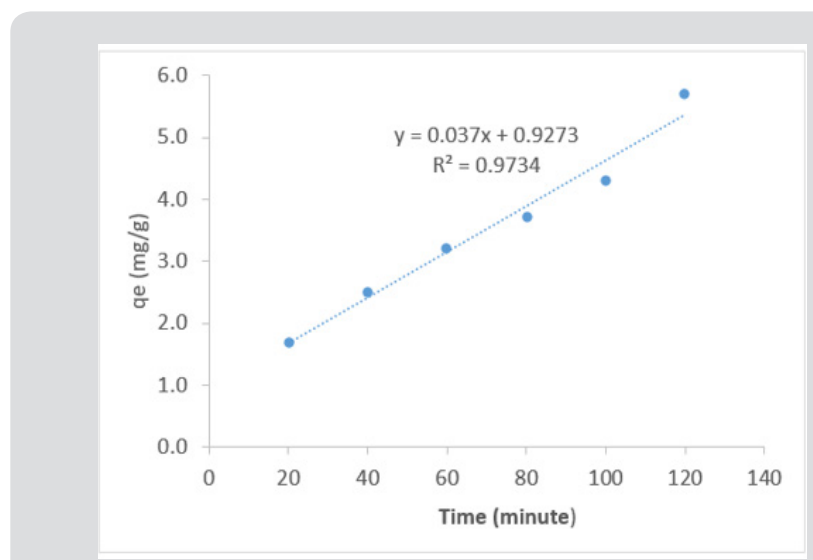

Figure 3: Variation of equilibrium amount of $B$ dye adsorbed with period of contact.

As several studies have revealed that adsorption capacity of a given adsorbent for dye depends on several factors including period of contact, $\mathrm{pH}$, concentration of the dye, adsorbent dose, modification of the dye, etc. Effect of most of these factors on the adsorption of methylene blue dye on ground nut shell surface were investigated in this work. Figure 3 shows the plot for the variation of equilibrium concentration of MB dye absorbed with concentration. The plot displays linear relationship between the amount of MB dye adsorbed and concentration indicating that the amount of MB dye adsorbed by ground nut shell increases with increasing concentration. For a given number of vacant desorption 
sites, increase in concentration of the adsorbate can increase the amount of dye that is adsorbed through corresponding increase in the rate of diffusion of the dye molecules to the adsorption site. Linear relationship was also observed between the amount of MB dye adsorbed and time, which also implies that with increasing time the amount of dye adsorbed will increase. This linear relationship observed for time and concentration parameters may not be observed beyond certain concentration and time.

The observed trend is similar to those reported in literature. Specifically, at the start of the experiment, available adsorption sites are gradually occupied as MB dye diffuses to the surface but beyond a certain concentration and at a certain time, vacant sites must have been completely covered hence competition between adsorption and desorption will set in leading to desorption and consequent decrease in the amount of adsorbed dye [30]. The amount of dye adsorbed on ground nut shell was also found to increase with increase in the adsorbent dose (as shown in Figure 4) up to a dose value of $6 \mathrm{~g}$, after which the equilibrium amounts adsorbed decreases. This observation signifies that there is a maximum dose of the adsorbent that will enhance efficient adsorption. Similar observation has been reported by other researchers [31]. Adsorption dosage can increase or decrease the amount of dye that is adsorbed based on the possibility of alteration of sticking probability arising from interaction between the adsorbent particles. If the interaction between the particles of the adsorbent is strong, the tendency for the dye to be adsorbed will decrease and vice versa.

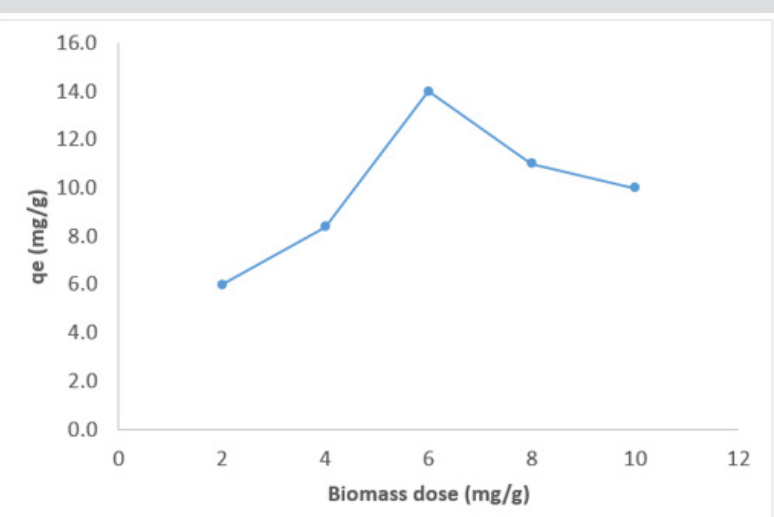

Figure 4: Variation of equilibrium amount of $\mathrm{MB}$ dye adsorbed with biomass dose.

A progressive increase in the amount of MB dye adsorbed with $\mathrm{pH}$ was also observed in this work (Figure 5). However, beyond the $\mathrm{pH}$ of 4 , the equilibrium concentration of MB dye adsorbed was constant. The trend can be attributed to effect of protonation by available hydrogen ion. At low $\mathrm{pH}$, the concentration of $\mathrm{H}^{+}$is enough to encourage adsorption of the dye because MB dye is anionic. However, progressive increase in $\mathrm{pH}$ leads to corresponding depletion of $\mathrm{H}^{+}$and subsequent reduction in the amount of dye adsorbed such that further increase in $\mathrm{pH}$ does not lead to a corresponding increase in equilibrium amount of adsorbed dye.

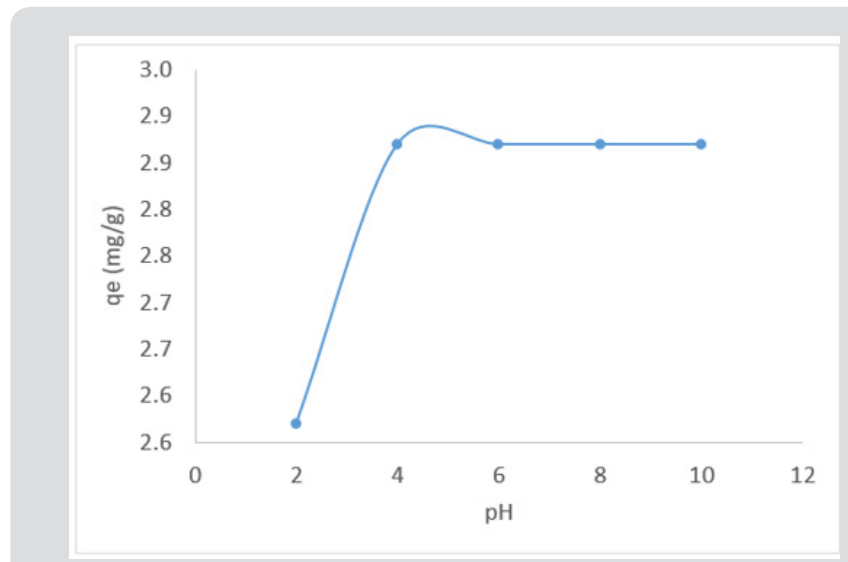

Figure 5: Variation of equilibrium amount of $\mathrm{MB}$ dye adsorbed with $\mathrm{pH}$.

\section{Kinetic Study}

The linear relationship established between equilibrium amount of MB dye adsorbed and time implies that the adsorption of MB dye significantly depends on time, hence kinetic study of the adsorption process is essential and relevant. Basic concepts of kinetics modelling of adsorption phenomenon is based on three major theories, namely, pseudo first order, pseudo second order and intra particle diffusion model. Curve fittings using equations applicable to the listed theories indicated that the adsorption of methyl blue dye on ground nut shell obeys all the relevant equations, except pseudo first order kinetic. A pseudo second order kinetics can be expressed in form of four models expressed as equations 2 to 5 [32].

$$
\begin{aligned}
\frac{t}{q_{e}} & =\frac{1}{k_{2} q_{e}^{2}}+\frac{1}{q_{e}} t \\
\frac{1}{q_{e}} & =\frac{1}{q}+\left(\frac{1}{k^{2} q_{e}^{2}}\right) \frac{1}{t} \\
q_{t} & =q_{e}-\left(\frac{1}{k q_{e}}\right) \frac{q}{t} \\
\frac{q_{e}}{t} & =k q_{t}^{2}-k q_{e} q_{t}
\end{aligned}
$$

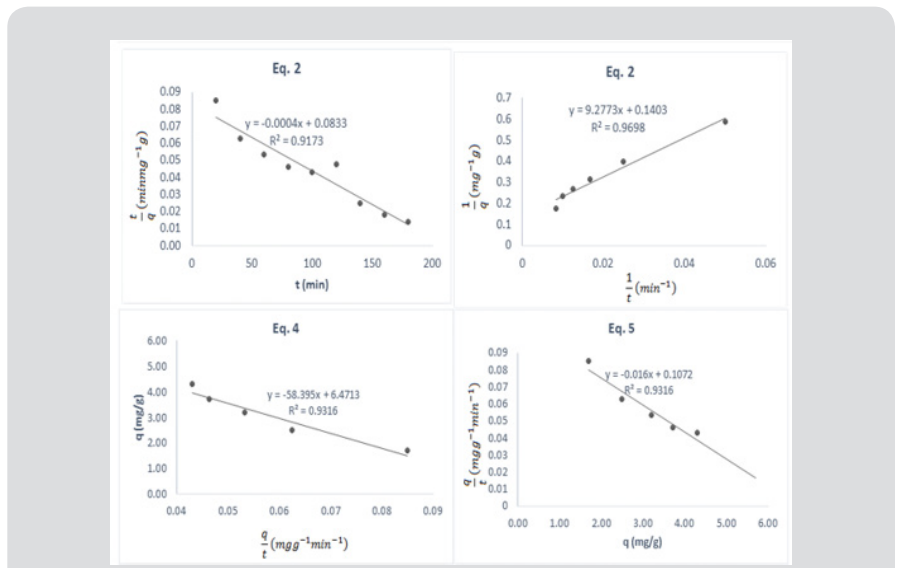

Figure 6: Pseudo second order kinetic plots for the adsorption of MB dye by ground nut waste.

According to equations 2, a plot of $\mathrm{t} / \mathrm{q}$ versus t is linear. Equation 3 requires that a plot of $1 / \mathrm{q}$ versus $1 / \mathrm{t}$ is linear while equations 4 
and 5 imply that plots of $q$ versus $q / t$ and $q / t$ versus $q$ are linear respectively. Pseudo second order kinetic plots based on equations 2 to 5 are presented in Figure 6 while kinetic parameters obtained from slope and intercepts of the plots are presented in Table 1. High degree of fitness were obtained for all the plots and the calculated pseudo second order parameters are relatively comparable to each other, indicating that the adsorption of MB dye obeys a pseudo second order kinetic. A significant feature of a pseudo second order model is the ability to calculate the initial adsorption rate, $\mathrm{h}$ and half adsorption time, $\mathrm{t}_{1 / 2}$ according to equation 6 and 7 respectively,

$$
\begin{aligned}
& h=\frac{1}{k_{2} q_{e}{ }^{2}} \\
& t_{\frac{1}{2}}=\frac{1}{k_{2} q_{e}}
\end{aligned}
$$

Table 1: Kinetic parameters for pseudo second order plots according to equations 2 to 5 .

\begin{tabular}{|c|c|c|c|c|c|}
\hline Equation & $\mathrm{q}_{\mathrm{e}}(\mathrm{mg} / \mathrm{g})$ & $\begin{array}{c}\mathrm{k}_{2}(\mathrm{~g} / \mathrm{mg} / \\
\mathrm{min})\end{array}$ & $\mathrm{h}$ & $\mathrm{t}_{1 / 2}(/ \mathrm{min})$ & $\mathrm{R}$ \\
\hline Eq. 2 & 8.25 & 0.0011 & 12.8742 & 106.212 & 0.9173 \\
\hline Eq. 3 & 7.1276 & 0.0021 & 9.2773 & 66.1247 & 0.9698 \\
\hline Eq. 4 & 6.4713 & 0.0026 & 9.0237 & 58.395 & 0.9316 \\
\hline Eq. 5 & 6.7 & 0.0027 & 8.1066 & 54.3144 & 0.9316 \\
\hline
\end{tabular}

Calculated $\mathrm{h}$ and $\mathrm{t}_{1 / 2}$ values for MB dye according to equations 2 to 5 are also presented in Table 1. The results obtained reveal that $h$ value for MB dye ranged from 8.11 to 12.87 while the $t_{1 / 2}$ values ranged from 54.31 to $106.21 / \mathrm{min}$. These values are comparable to values reported for the adsorption of some dyes by ground nut shell [30]. Adsorption of MB dye on ground nut shell may involves diffusion process as the rate limiting step provided the intra particle diffusion model (equation 8) is obeyed.

$$
q_{e}=k_{p} t \frac{1}{2}
$$

where $\mathrm{kp}$ is the intra particle diffusion constant. Figure 7 shows that a plot of $\mathrm{q}_{\mathrm{e}}$ versus $\mathrm{t}^{(1 / 2)}$ was linear with Kp value of 1.66. Generally, most plots for intra particle diffusion models may exhibit three sections. The first section is the slowly rising graph followed by a straight line and lastly a plateau. However, in this study, the plot is completely linear, which confirms that both surface adsorption and intra particle diffusion process occur simultaneously.

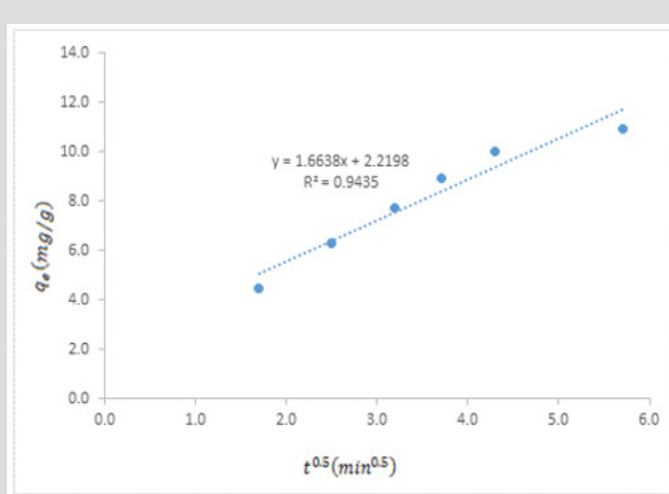

Figure 7: Intra particle diffusion model plot for the adsorption of MB dye on ground nut shell.

\section{Adsorption Isotherm}

An investigation into the best suited model that describes the adsorption characteristics of MB dye on ground nut shell revealed that Langmuir and isotherm best fitted the adsorption of MB dye on ground nut shell. The Langmuir adsorption equation can be written as [33-39].

$$
\frac{c_{e}}{q_{e}}=\frac{1}{k_{L} q_{m}} \frac{c_{e}}{q_{m}}
$$

Figure 8 shows the Langmuir plot for the adsorption of the studied dye on ground nut shell. From the slope of the plot, calculated value of the theoretical adsorption capacity $\left(\mathrm{q}_{\mathrm{m}}\right)$ is $4.4703 \mathrm{mg} / \mathrm{g}$ while the Langmuir adsorption constant $\left(\mathrm{k}_{\mathrm{L}}\right)$ is 0.112327 . The separation factor, $\mathrm{R}_{\mathrm{L}}$, expressed as $R_{L}=\frac{1}{1+K_{L} C_{e}}$ were found to range from 0.1511 to 0.4710 and increase with increase in the concentration of the dye. Therefore, the adsorption of MB dye on ground nut shell surface is favorable since RL is less than unity but greater than zero [7]. The standard Gibb free energy of adsorption of MB dye on ground nut shell was evaluated using the Gibb Helmholtz equation (equation 10)

$$
\Delta G_{a d s}{ }^{0}=-R T \ln K_{T} \quad 10
$$

Application of equation 10 resulted in the average value of $5507.70 \mathrm{~J} / \mathrm{mol}$ for the $\Delta G_{a d s}{ }^{0}$.This value is lower than the threshold value expected for the mechanism of physical adsorption. Therefore, the adsorption of MB dye on ground nut shell is consistent with the mechanism of physical adsorption.

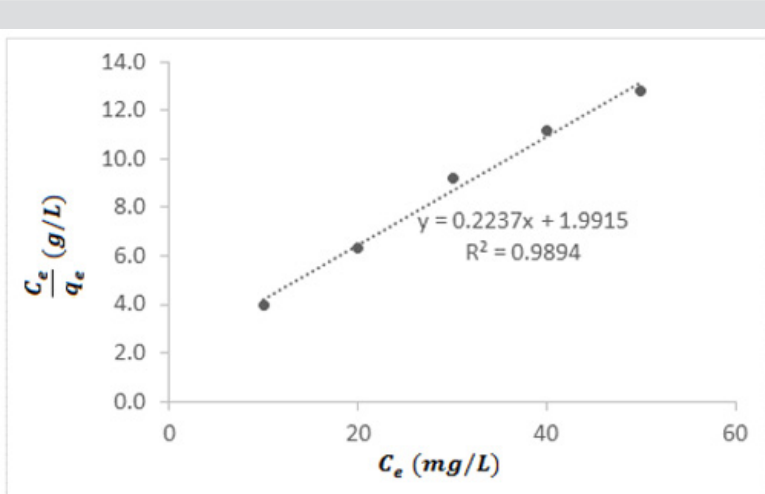

Figure 8: Langmuir isotherm for the adsorption of MB dye on ground nut shell.

\section{Conclusion}

The present study was designed to investigate the adsorption capacity of ground nutshell for methylene blue dye. The results and findings of the study conform that ground nut shell is a good adsorbent for the removal of methylene blue dye from aqueous solution. The removal efficiency of ground nut shell for methylene blue dye is favored by the present of suitable functional groups and the adsorption capacity can be optimized by taking advantage of period of contact, concentration of the adsorbate, mass of the adsorbent, pH. The adsorption of methylene dye unto ground nut shell fitted pseudo order model and the Langmuit adsorption 
isotherm. Therefore, ground nut is an excellent adsorbent for the removal of methylene blue dye from aqueous solution.

\section{References}

1. Ratna PBS (2012) Pollution due to synthetic dyes toxicity and carcinogenicity studies and remediation. International J Environ Sci 3(3): 940-955.

2. Klemola K, Pearson J, Lidstrom-Seppa P (2007) Evaluating the toxicity of reactive dyes and dyed fabrics with the heap-1-cytotoxicity test. AUtex Res J 7(3): 224-230.

3. Reddy PMK, Verma P, Subrahmanyam C (2016) Bio-waste derived adsorbent materials for methylene blue adsorption. J Taiwan Institute of Chemical Engineers 58: 500-508.

4. Ventura Camargo BD, Marin Morales MA (2013) Azo dyes: Characterization and toxicity- A review. Textile Light Industrial Sci Tech (TLIST) 2(2): 65-103.

5. Ventura Camargo BD, Marin Morales MA (2013) Azo dyes: Characterization and toxicity- A review. Textile Light Industrial Sci Tech (TLIST) 2(2): 65-103.

6. Peng J, Qu J, Zhang J, Chen M, Wan T (2005) Adsorption characteristics of water reducing agents on gypsum surface and its effect on the rheology of gypsum plaster. Cement and Concrete Research 35(3): 527-531.

7. Deniz F, Saugideger SD (2010) Investigation of adsorption characteristics of basic red 46 onto gypsum: equilibrium, kinetic and thermodynamic studies. Desalination 262 (1-3):161-165.

8. Dolphen R, Sakkayawong N, Thiravetyan P, Nakbanpote W (2007) Adsorption of reactive red dye 141 from wastewater onto modified chitin. J Hazardous Materials 145 (1-1): 250-255.

9. Annadurai G, Ling LY, Lee JF (2008) Adsorption of reactive dye from aqueous solution by chitosan: isotherm, kinetic and thermodynamic analysis. J Hazard Mater 152(1): 337-346.

10. Sakkayawong N, Thiravetyan P, Nakbanpote W (2005) Adsorption mechanism of synthetic reactive dye wastewater by chitosan. Journal of Colloid and Surface Science 1: 36-42.

11. Uzum I (2006) Kinetics of the adsorption of reactive dyes by chitosan Dyes and Pigments 70(2): 76-83.

12. Wang S, Ariyanto E (2007) Competitive adsorption of malachite green and lead on natural zeolite. J Colloids Interface Sci 314: 25-31.

13. Miyah Y, Lahrichi A, Idrissi M, Khalil A, Zerrouq F (2018) Adsorption of blue dye from aqueous solutions onto walnut sheels powder: Equilibrium and kinetic studies. Surfaces and interfaces. 11: 74-81.

14. Rehman MSU, Kim I, Rashid N, Umer MA, Sajid M, et al. (2015) Adsorption of brilliant green dye on Biochar prepared from lihnocellulosic bioethanol plant waste. CLEAN-soil Air Water 44(1): 55-62.

15. Munagapati VS, kim, D (2016) Adsorption of anionic azo dye congo red from aqueous solution by cationic modified orange peel powder. ] molecular Liquids 220: 540-548.

16. Sivaraj R, Namasivayam C, Kadirvelu K (2001) Orange peel as an adsorbent in the removal of acid violet 17 (acid dye) from aqueous solutions. Waste management 21: 105-110.

17. Palaez Cid A, Herrera Gonzalez A, Salazar Villanueva M, Bautista Hemadez A (2016) Elimination of textile dyes using activated carbons prepared from vegetable residues and their characterization. Journal of Environmental Management 181: 269-278.

18. You H, Chen J, Yang C, Xu L (2016) Selective removal of cationic dye from aqueous solution by low cost adsorbent using phytic acid modified wheat straw. Colloids and Surface A: Physicochem Engineer Aspects 509: 91-98.

19. Viera SS, Magriotis ZM, Santos NAV, Cardoso MD, Saczk AA (2012) Macauba palm (Acrocomia aculeate) cake from biodesel processing: An efficient and low cost substrate for the adsorption of dyes. Chem Engineer J 183:152-161.
20. Subramaniam R, Ponnusamy SK (2015) Novel adsorbent from agricultural waste (cashew nut shell) for methylene blue dye remova: Optimization by response surface methodology. Water Resources Industry 11: 64-70.

21. Setiabudi HD, Jusoh R, Suhaimi SFM, Masrur SF (2016) Adsorption of methylene blue unto oil palm (Elaeis guineensis) leaves: Process optimization, isotherm, kinetics and thermodynamic studies. J Taiwan Institute Chem Engineer 63: 363-370.

22. Shen K, Gondal MA (2017) Removal of hazardous rhodamine dye from water by adsorption onto exhausted coffee ground. Journal of Saudi Chem Society 21: 120-127.

23. Markovic A, Stankovic A, Lopicic Z, Lazarevic S, Stojanovic M, et al. (2015) Application of raw peach shell particles for removal of methylene blue. J Environ Chem Engineer 3(2): 716-724.

24. Garba ZN, Bello I, Galadima A, LawalAY (2016) Optimization of adsorption conditions using central composite design for the removal of copper (II) and lead (II) by defatted papaya seed. Karbala International J Modern Sci 2(1): 20-28

25. Adegoke KA, Bello OS (2015) Dye sequestration using agricultural wastes as adsorbents. Water Resources Industry 12: 8-24.

26. Postai DL, Demarchi CA, Zanatta F, Melo DCC, Rodrigues A (2016) Adsorption of rhodamine $\mathrm{B}$ and ethylene blue dyes using waste of seeds of Aleurite moluccana, a low-cost adsorbent. Alexandria Engineer J 55(2): 1713-1723.

27. Kumar S, Gunasekar V, Ponnusami V (2013) Removal of methylene blue from aqueous effluent using fixed bed of groundnut shell powder. J Chem pp. 5.

28. Borah L Goswami, M Phukan P (2016) Adsorption of methylene blue and eosin yellow using porous carbon prepared from tea waste: Adsorption equilibrium kinetics and thermodynamics study. J Environ Chem Engineer 3(2): 1018-1028.

29. Balarak D, Jaafari J, Hassani G, Mahdavi Y, Tyagi, et al. (2015) The use of low-cost adsorbent (Canola resides) for the adsorption of methylne blue from aqueous solution: Isotherm, kinetic and thermodynamic studies. Colloids Interface Sci Commun 7: 16-19.

30. Li Z, Wang G, Zhai W, He C, Li Q, et al. (2018) Methylene blue adsorption solution by loofah sponge-based porous carbons. Colloids and Surfaces A Physicochem Engineer Aspects 538: 28-35.

31. Odoemelam SA, Emeh NU, Eddy NO (2018) Experimental and computational Chemistry studies on the removal of methylene blue and malachite green dyes from aqueous solution by neem (Azadiractha indica) leaves. Journal of Taibah University of Science 12(3): 255-265.

32. Ghaedi M, Shojaeipour E, Ghaedi AM, Sahraei R (2015) Isotherm and kinetics study of malachite green adsorption onto copper nanowires loaded on activated carbon: Artificial neural network modeling and genetic algorithm optimization. Spectrochim Acta A Mol Biomol Spectrosc 142: 135-149.

33. Kumar KV (2006) Linear and nonlinear regression analysis for the sorption kinetics of methylene blue onto activated carbon. J Hazardous Mater B 137(3): 1538-1544.

34. Islam MA, Benhouria A Asif M, Hameed BH (2015) Methylen blue adsorption on factory rejected tea activated carbon prepared by conjuction of hydrothermal carbonization and sodium hydroxide activation processes. J Taiwan Institute of Chem Engineer 52: 57-64.

35. Mahmoud ME, Nabi GM, El Mallah NM, Bassiouny HI, Kumar S, et al. (2016) Kinetics, isotherm and thermodynamic studies of the adsorption of reactive red 195 A dye from water by modified switch grass bio char adsorbent. J Industrial Engineer Chem 37: 156-167.

36. Manna S, Roy D, Saha P, Gopakumar D, Thomas S (2017) Rapid methylene blue adsorption using modified lignocellulosic materials. Process Safety Environ Protect 107: 346-356.

37. Peláez Cid AA, Velázquez Ugalde I, Herrera González AM, García Serrano J (2013) Textile dyes removal from aqueous solution using Opuntiaficus 
indica fruit waste as adsorbent and its characterization. J Environ Manage 130: 90-97.

38. Shakoor S, Nasar A (2016) Removal of methylene blue dye from artificially contaminated water using citrus limetta peel waste as a very low-cost adsorbent. Journal of Taiwan Institute of Chem Engineers 66 : 154-163.

\section{ISSN: 2574-1241}

DOI: 10.26717/BJSTR.2019.15.002701

Esther Unyime Etim. Biomed J Sci \& Tech Res

cC (i) This work is licensed under Creative Commons Attribution 4.0 License

Submission Link: https://biomedres.us/submit-manuscript.php
39. Verma Y (2008) Acute toxicity assessment of textile dyes and textile and dye industrial effluents using Daphinia magna bioassay. Toxicol Ind Health 24(7): 491-500.

$\begin{array}{ll}\text { BIOMEDICAL } & \text { Assets of Publishing with us } \\ \text { RESEARCHES } & \text { - Global archiving of articles } \\ \text { - Immediate, unrestricted online access } & \text { - Rigorous Peer Review Process } \\ & \text { - Authors Retain Copyrights }\end{array}$

